\title{
O PrivilégIo da SERVIDÃo: O NoVo PROLETARIAdo de SERVIÇOS NA ERA DIGITAL
}

\author{
The privilege of servitude: the new proletariat of services in the digital age \\ El privilegio de la servidumbre: el nuevo proletariado de servicios en la era \\ digital
}

ANTUNES, Ricardo. 0 privilégio da servidão: o novo proletariado de serviços na era digital. São Paulo: Boitempo, 2018.

Ricardo Antunes é professor titular da Universidade Estadual de Campinas - UNICAMP, sociólogo e estudioso das relações entre capital e trabalho na perspectiva marxista. $O$ autor traz em seu novo livro, lançado em 2018: O privilégio da servidão: o novo proletariado de serviços na era digital. Uma leitura impactante, clara e objetiva, ainda que esses adjetivos não signifiquem que seja uma leitura fácil. Composto por 325 páginas, divididas em quatro partes, Antunes objetiva compor um panorama global de formação da nova classe trabalhadora da era digital, denominada por ele como o proletariado de serviços. Pode-se considerar esse livro uma fonte intensa de informações para estudiosos e pesquisadores das relações entre o mundo do trabalho e a sociedade, como sociólogos, historiadores e educadores, por exemplo.

Na parte I do livro, Antunes inicia seu texto desmistificando a ideia de que, com o avanço das tecnologias de informação e comunicação (TICS), haveria uma transformação positiva em escala global, onde, utopicamente, a sociedade digitalizada nos levaria ao fim do trabalho. Definido pelo autor como um discurso eurocêntrico e de pouca reflexão, podemos relacioná-lo diretamente com o discurso relacionado à chamada Indústria 4.0, por exemplo. Fundamentalmente, a sociedade globalizada e digitalizada não acabou com o labor, ao contrário, criou uma nova morfologia do trabalho, gerando uma nova classe trabalhadora do hoje, um novo proletariado de serviços: heterogênea, fragmentada, instável. Diminuição de salários, perda de direitos trabalhistas, precarização, terceirização e informalidade são algumas das consequências. Ao final, Antunes nos faz uma provocação: "Que estranho mito foi esse do fim do trabalho dentro do capitalismo?"

Para entender essa nova morfologia do trabalho, que tende mais a escravizar do que a libertar e visando entender essa face do capitalismo contemporâneo, foi inevitável para o autor retornar a Marx (1978) em O capital, tendo em vista compreen-

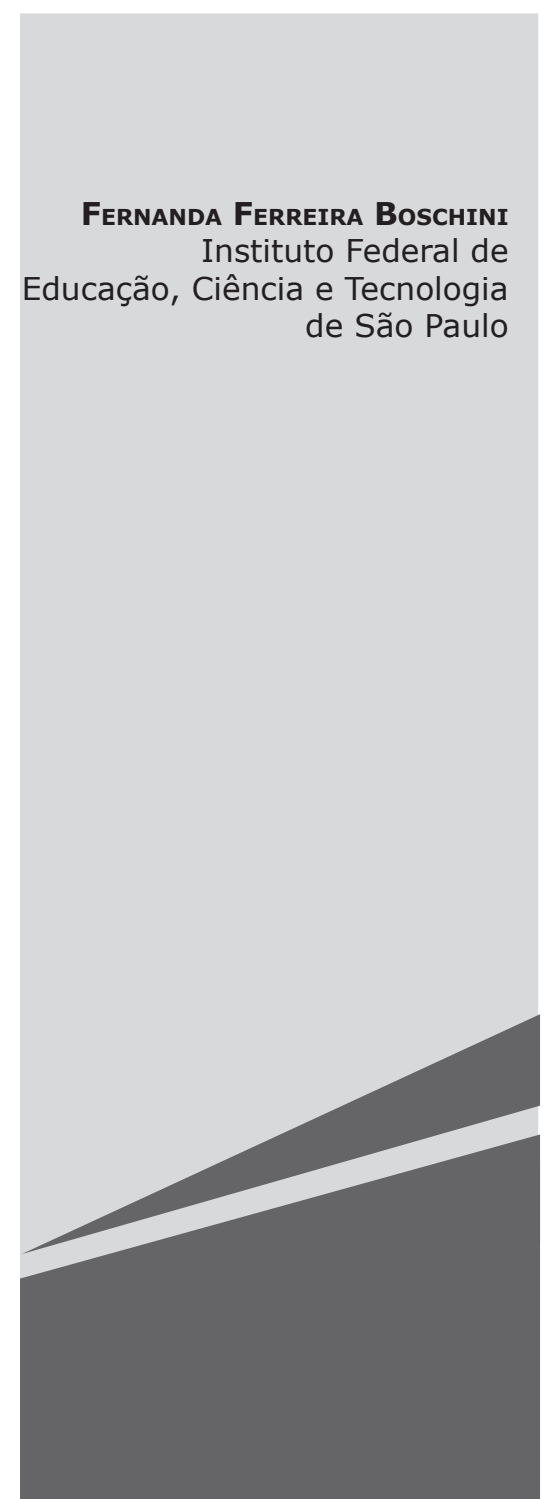


der, principalmente, nessa nova divisão do trabalho, qual o papel da indústria de serviços na acumulação de capital. Antunes (2018) defende a tese de que, por meio das privatizações, estamos presenciando novas formas de extração de mais valor e de trabalho produtivo, impulsionadas pela terceirização e a contratação de trabalhadores de serviços como call centers, hipermercados ou redes de fast-food por exemplo. Em sua hipótese, Antunes (2018) classifica esses sujeitos como o novo proletariado de serviços. Novamente, o autor faz uma provocação: Classe média ou novo proletariado de serviços? Se, por um lado, o mundo da classe média parece se aproximar da classe dominante, por outro lado ela é incerta, já que depende quase que exclusivamente dos empregos assalariados e é diretamente afetada pelas mudanças dos setores produtivos. Podemos considerá-la, na visão do autor, uma extensão da classe trabalhadora, porém sem "consciência de classe". Seria essa uma nova classe?

Em O Privilégio da Servidão, Ricardo Antunes também cita o conceito do autor canadense de Guy Standing (2011) em O Precariado, a nova classe perigosa. Ainda que Standing defina o precariado como uma "nova classe", que surgiu após a era Taylorista/Fordista, Antunes aparenta ir na contraposição e assume uma posição crítica ao trabalho de Standing, ao definir o precariado como apenas uma parcela do proletariado. Apesar do cenário apresentado por Antunes (2018) parecer desolador, ele lembra ao leitor de que a precarização, apesar de ser intrínseca ao capitalismo, se desenvolve em um processo que pode tanto se ampliar quanto se reduzir, mas que depende da capacidade de resistência, organização e confrontação da classe trabalhadora.

Na parte 2, o autor opta por caracterizar essa nova morfologia do trabalho no Brasil e sua reestruturação produtiva, que ocorreu a partir dos anos de 1990 com o assentamento das políticas neoliberalistas no país e as privatizações estatais. Para retratar fielmente essa morfologia desenvolvida nos governos Collor-FHC-Lula, Antunes (2018) explica a in- tensificação da força de trabalho com o tripé que sustentou a economia brasileira nas últimas três décadas: a indústria metalúrgica, a agroindústria de exportação e o setor de serviços de telemarketing. Ambos os setores são exemplos claros de superexploração do trabalho: maior intensidade e produtividade (extensão de jornadas e trabalho por produção), redução de piso salarial, rigoroso controle de tempo, metas inalcançáveis, lesões e acidentes de trabalho. Para o autor, esse conjunto de trabalhadores expostos a essas condições precarizadas compõe a nova morfologia do trabalho no Brasil. A análise de Antunes (2018) é similar à realizada por Ruy Braga (2012), em A política do precariado: do populismo à hegemonia lulista (EDITORA BOITEMPO, 2012), em que o autor já identifica o descontentamento dos trabalhadores brasileiros (chamado por ele de precariado brasileiro) com as condições de trabalho, estudo complementado posteriormente pelo livro A rebeldia do precariado: trabalho e neoliberalismo no sul global, também de Ruy Braga (2017), que, de certa forma, converge com o texto de Antunes (2018).

No texto de Antunes (2018), ao traçar um panorama entre os novos processos produtivos e os acidentes de trabalho ao longo do século XX, percebe-se que, quanto mais flexível e precarizado o trabalho se torna, mais os trabalhadores se encontram expostos às doenças laborais. E essa proporcional relação desmistifica a ideia capitalista amplamente difundida de que: quanto mais tecnologia tanto menos acidentes. Os trabalhadores não deixaram de adoecer e sim as doenças que mudaram ao longo dos anos. Gestão por metas, controle excessivo, flexibilização salarial, falta de autonomia e assédio são alguns dos causadores principais de diversas doenças provenientes do meio laboral do trabalhador que afetam o corpo e a mente, como as doenças psíquicas - o suicídio no local de trabalho também é registrado no livro como uma terrível consequência da solidão imposta pelo processo de racionalização e individualização do trabalho em sua forma mais selvagem. Esse mesmo trabalhador ain- 
da é submisso ao discurso de valorização de suas potencialidades individuais, que vive em um ambiente competitivo, instável, tentando manter-se empregado a todo instante. Quando parece que Antunes (2018) já destrinchou em seu texto todas as consequências das novas relações de trabalho, surgem novos tipos de superexploração do trabalho A cada página lida, percebemos, com a leitura que fazemos, parte dessa massa trabalhadora precarizada.

Antunes (2018) descreve como o "novo sindicalismo brasileiro", o movimento operário surgido entre os anos de 1970 e 1980, nascido sob as consequências do golpe militar de 1964. Distanciando-se do caráter assistencialista e se organizando politicamente foi a base da criação da Central Única dos Trabalhadores (CUT) e do Partido dos Trabalhadores (PT). Em oposição à exploração do trabalho e a uma tendência neoliberal (internacional inclusive), o autor remete aos anos de 1980, vitoriosa para os movimentos sindicais/sociais, não ficando esquecidas na memória as grandes greves do período. Segundo Antunes (2018), tudo isso não só resultou em implementações significativas na Constituição de 1988, como na chegada de um representante sindical nas eleições presidenciais em 1989. A década de 1990, chamada diretamente pelo autor como "década neoliberal", foi de muita pressão para os sindicatos, principalmente pela consolidação dos novos processos produtivos. Outras políticas foram sendo inseridas. O "novo sindicalismo" se tornou "novo de novo". Ainda que a palavra "novo" remeta a progresso, o autor deixa claro o caráter regressivo das organizações sindicais, ao trazer o sindicalismo para um contexto de negociações e transformando os trabalhadores em "gestores" sindicais. No início do capítulo 12, Antunes (2018) indaga sugestivamente: Para onde foram os sindicatos?

A chegada dos sindicalistas ao poder ocorreu apenas em 2002, por meio de Luís Inácio Lula da Silva, o Lula, já em um contexto neoliberal herdado do governo Fernando Henrique Cardoso, com a proposta de manter os interesses capitalistas, desorientando as propostas sindicais, que passaram a trabalhar muito mais com a discussão de temas sociais (racismo, gênero, desemprego) do que com suas bases estruturais, que se pautam na defesa de uma classe trabalhadora. Durante o governo Lula, a CUT e a Força Sindical participaram ativamente do governo. $O$ atrelamento ao Estado, antes combatido, passou à dependência política, ideológica e financeira.

Com a parte 3, Antunes (2018), ao buscar traçar um panorama da crise brasileira e trazer ao leitor, cronologicamente, a partir do primeiro mandato do governo Lula até o segundo mandato da presidenta Dilma Rousseff como que se desenhou, nas palavras do autor "a construção e a corrosão do mito", pode-se perceber uma crítica intensa e realista aos mandatos do Partido dos Trabalhadores que ocorreram entre 2002 e 2016. Ao criar uma forte política assistencialista para os mais pobres, e ao mesmo tempo preservar os grandes capitais, seu governo se transformou, nas palavras do autor, em policlassista. Sua aproximação se concentrou nos lados opostos da pirâmide (os mais pobres e os mais ricos). Pode-se dizer, ainda, que com a questão social sendo trabalhada em uma perspectiva assistencialista, e não redutora das desigualdades, houve uma política clara de favorecimento ao capital. O capital lucrou em números nunca antes vistos. Apesar de alguns programas de governo como o Bolsa Família beneficiarem e muito os setores mais carentes da sociedade, segundo Antunes (2018), "nenhum dos pilares estruturantes da miséria foi efetivamente enfrentado" (p. 229).

Segundo Antunes (2018), as rebeliões de junho de 2013 surgiram por um transbordamento dos múltiplos descontentamentos. Iniciadas após o levante de uma juventude, que tinha como demanda o transporte público em São Paulo, logo se espalhou para diversos grupos, com a singularidade policlassista que era constituída tanto do precariado jovem (indivíduos com acesso ao trabalho, à saúde e à educação precarizados), assim como movimentos sociais de vários tipos e a classe média destruída, endividada. Novas reinvindi- 
cações foram aderindo às manifestações, que foram crescendo exponencialmente. Ainda que o mal-estar social tenha sido um dos catalisadores, com o princípio das manifestações consideradas "apartidárias" e ligadas a setores concebidos "de direita", as manifestações também trouxeram uma polarização política, que resultou em uma vitória apertada para o PT, na reeleição de Dilma Rousseff, em 2014, e finalmente, no golpe de 2016, que se materializou no impeachment da então presidenta.

Para Antunes (2018), os governos Lula e Dilma, de perfil conciliatório, andaram muito bem, enquanto as condições econômicas estavam favoráveis. Porém, com os escândalos de corrupção, com a Operação Lava Jato, o agravamento da crise econômica, o aumento da inflação, a redução dos empregos atingiu em cheio a classe média baixa. Nas classes médias, de perfil mais conservador, desenvolveu-se um ódio contra a denominada "esquerda", do PT de Lula e Dilma. O autor se mostra claro em sua crítica, ao afirmar que apesar do golpe parlamentar e judicial, ancorado pela mídia, que resultou no impeachment, não se deve ser condescendente com as "práticas de corrupção político-eleitoral” presentes nos governos petistas, ainda que essas práticas sejam recorrentes na história republicana brasileira. A contrarrevolução, citada por Antunes (2018), vem no sentido da prevenção ultraneoliberal em sua fase mais agressiva, com a finalidade de preservar os interesses da classe dominante no país, ao privatizar o que ainda resta estatizado, e realizar a demolição completa dos direitos trabaIhistas no Brasil, como podemos observar no perfil do governo de Michel Temer, ao propor medidas que caminham para a flexibilização total das relações de trabalho. Toda essa conjuntura política, analisada por Antunes (2018), trabalha em um tipo de projeto de desconstrução do trabalho no Brasil.
Na parte IV, intitulada com a sugestiva frase Há uma luz no fim do túnel?, todo o processo de desmonte dos direitos do trabalho se mostra sob o levante da, segundo o autor, contrarrevolução de Temer. Esse quadro desenhado no livro afeta diretamente tudo que representa a classe trabalhadora. Antunes (2018), então, provoca uma reflexão no leitor: Ainda há espaço para os sindicatos nesta nova morfologia do trabalho? Para ele sim e ainda indica alguns desafios que, se enfrentados, poderão, nas palavras do autor, "revitalizar" os organismos sindicais. Ao final, mais uma provocação: Qual é o futuro da classe trabalhadora no capitalismo? Talvez tenha faltado a Antunes (2018), nesse livro, uma crítica mais aprofundada à questão sindical e às distorções muitas vezes ocorridas em suas atuações nas últimas décadas.

Caminhando para o final do livro, Antunes (2018) afirma que a busca por um novo projeto socialista se torna vital em um mundo em que o capitalismo se tornou tão destrutivo. Ainda que as experiências socialistas, no século XX, tenham sido derrotadas (o autor cita os exemplos da URSS e da China). Entender a História e ser crítica a ela se torna essencial na compreensão ao passado e seus erros para que se possa criar novas formas de uma luta política e social internacional contra o domínio do capital em um processo emancipatório por uma nova maneira de trabalho e, por conseguinte, por um novo modo de vida. Ao invés de subordinação e alienação, deve-se buscar um sentido no trabalho, e um tempo livre e autônomo fora dele (p. 305). Já a reflexão final nos desafia novamente, quando Antunes (2018) diz que: "Se o mundo atual nos oferece como horizonte imediato o privilégio da servidão, seu combate e seu impedimento efetivos, então, só serão possíveis se a humanidade conseguir recuperar o desafio da emancipação" (ANTUNES, 2018, p. 306). 


\section{REFERÊNCIAS}

ANTUNES, R. O privilégio da servidão: o novo proletariado de serviços na era digital, 1. ed. São Paulo: Boitempo, 2018.

BRAGA, R. A política do precariado: do populismo à hegemonia lulista. São Paulo: Boitempo, 2012.

BRAGA, R. A rebeldia do precariado: trabalho e neoliberalismo no sul global. São Paulo: Boitempo, 2017.

MARX, K. O capital: livro 1 - Capítulo VI (inédito). São Paulo: Ciências Humanas, 1978.

Submetido em: 9-3-2019

Aceito em: 10-10-2019 